\title{
Case Report \\ Rare Case of Male Breast Cancer and Axillary Lymphoma in the Same Patient: An Unique Case Report
}

\section{Emiliano Sordi, ${ }^{1,2}$ Katia Cagossi, ${ }^{1}$ Maria Grazia Lazzaretti, ${ }^{1}$ Daniel Gusolfino, ${ }^{1}$ Fabrizio Artioli, ${ }^{1}$ Giovanni Santacroce, ${ }^{3}$ Maria Luisa Brandi, ${ }^{4}$ and Prisco Piscitelli ${ }^{4}$}

${ }^{1}$ Ramazzini Hospital, Division of Oncology, 41012 Carpi, Italy

${ }^{2}$ Italian Air Force Medical Corps, 72100 Brindisi, Italy

${ }^{3}$ Local Health Authority ASL Lecce, Division of Oncology, 73048 Nardò, Italy

${ }^{4}$ University of Florence, Department of Internal Medicine, 50139 Florence, Italy

Correspondence should be addressed to Prisco Piscitelli, priscofreedom@hotmail.com

Received 15 June 2011; Accepted 25 July 2011

Academic Editor: Jens Sondergaard

Copyright (๑) 2011 Emiliano Sordi et al. This is an open access article distributed under the Creative Commons Attribution License, which permits unrestricted use, distribution, and reproduction in any medium, provided the original work is properly cited.

Breast cancer in men is uncommon, and even more rare is the simultaneous presentation of two different malignancies. A 39-yearold man was diagnosed with both breast cancer and axillary lymphoma. Familiar history revealed that his mother died because of breast cancer. The patient underwent fine needle aspiration leading to the diagnosis of malignant lesion. Modified radical mastectomy was performed. Histology revealed an infiltrating ductal carcinoma $2.8 \mathrm{~cm}$ wide, grade 2, with vascular and lymphatic invasion. Surprisingly, one of the second level nodes was confirmed as a high-grade large B cell non-Hodgkin's lymphoma. No family inheritance or gene mutations (BRCA 1 and 2) were found. The patient underwent local radiotherapy, followed by 6 chemotherapy courses (RCHOP) and treatment with tamoxifen $20 \mathrm{mg} /$ daily. To our knowledge, this is the first case reported in literature of male breast cancer and axillary lymphoma simultaneously confirmed in the same patient.

\section{Introduction}

Male breast carcinoma (MBC) is very uncommon, accounting all over the world for almost $1 \%$ of all breast malignancies [1]. The annual incidence of male breast cancer in Europe has been estimated not to exceed 1 out 100,000 [2-4], and in the U.S. 1,690 new cases were diagnosed in the year 2005 with a $25 \%$ mortality rate [5]. This high mortality rate may be due to a delay between the onset of symptoms and diagnosis because of a limited awareness of breast cancer risk in males compared to women. While the incidence of female breast cancer is rising up, the incidence of male breast cancer remains almost stable throughout the world [6-8]. In male patients, the risk of developing breast cancer increases with age, and the highest incidence is observed between 5 and 10 years later if compared to women $[9,10]$. The annual incidence increases steadily from 35 years of age from 0.1 per 100,000 up to 11.1 per 100,000 in people aged $\geq 85$ years [9]. Optimal management of male breast cancer is not clearly established, and treatment guidelines have not been provided, maybe because most of the available literature consists of individual case reports. An international multicentric study of first and second primary neoplasms associated with male breast cancer, carried out on 3,409 patients by pooling data from 13 cancer registries, has found an increase of male breast cancers following lymphohematopoietic neoplasms [10]. Risk factors mainly involve abnormalities in oestrogen and androgen balance (i.e. patients with gynaecomastia, undescended testes, Klinefelter's syndrome, and people who underwent orchidectomy [11-24]. The authors describe here the first synchronous case reported in literature of male breast carcinoma in a young patient, who was simultaneously affected by an axillary lymphoma. Actually, the existing reports describe few similar cases only in women [25]. Currently, no relationship between the two diseases is known.

\section{Case Report}

A 39-year-old man with no significant medical history was examined as outpatient at the oncology department of Ramazzini Hospital in Carpi (Modena, Italy). The patient 


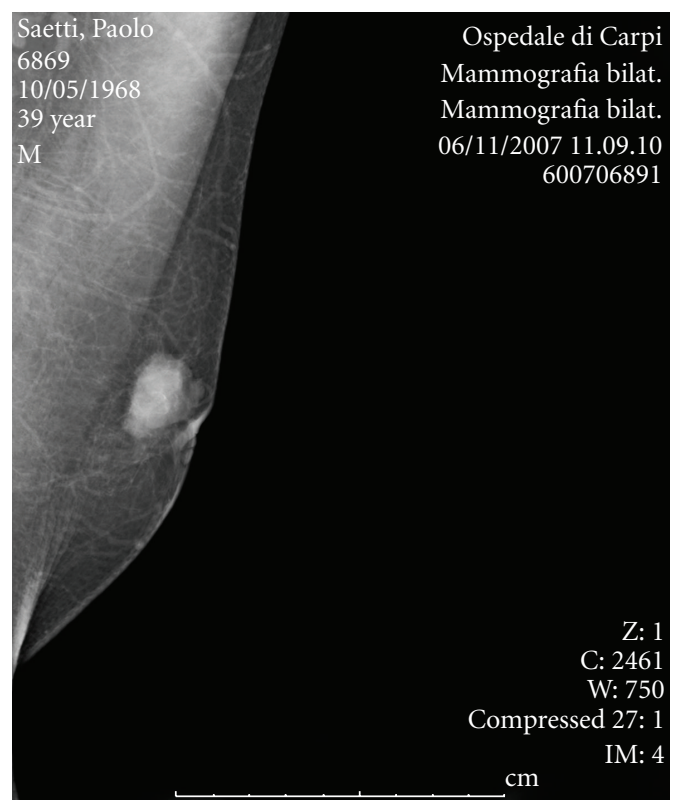

Figure 1

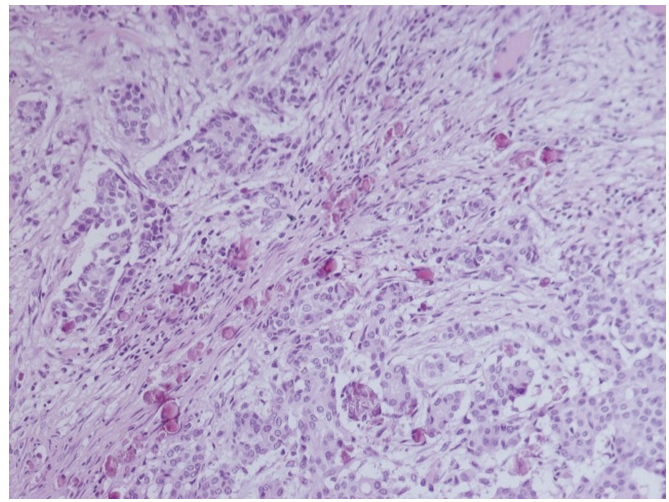

Figure 2

presented nipple retraction of his left breast, without nipple discharge. The physical examination revealed a $2 \mathrm{~cm}$ firm lump. Family history concerning parental diseases revealed that his mother died because of breast cancer. Conventional imaging showed an irregular mass lesion situated in the upper outer quadrant of the left breast (Figure 1). The patient underwent fine needle aspiration at our hospital, and the lump was diagnosed as a malignant lesion (C5 according to the European guideline 1997). The patient had no other associated diseases. He was not taking any medication nor suffering from any known drug allergy. Modified radical mastectomy was performed.

Histology revealed an invasive ductal carcinoma $2.8 \mathrm{~cm}$ wide, grade 2, with vascular and lymphatic invasion (Figure 2). Three axillary nodes of the 1 st level and two nodes of the 2nd level were found to be involved by metastatic breast carcinoma ( 4 nodes out of 21). Surprisingly, one of the second level nodes corresponded to a high-grade large B cell lymphoma. Further immunohistochemical staining revealed the lymphoma to be positive for CD20, CD79a, CD5 but negative for $\mathrm{CD} 3$. The lymphoma was evaluated as a large $\mathrm{B}$ cell non-Hodgkin's lymphoma, according to the WHO Classification. The staging of the disease was performed by using CT, PET, and bone scintigraphy; no other pathologic sites were identified. The International Prognostic Index (IPI) for the patient's non-Hodgkin's lymphoma was found to be $0^{*}[26]$. The patient was treated with local radiotherapy, followed by 6 courses of chemotherapy (RCHOP) before starting a treatment with tamoxifen using a dosage of $20 \mathrm{mg}$ daily. Genetic investigations were performed, but no family inheritance or gene mutations (BRCA 1 and 2) were found.

\section{Discussion}

Some published case reports have found two cancers in the same patient but not simultaneously [27, 28]. An interesting review concerning new malignancies among cancer survivors in the US has been published in 2006 by the National Institute of Health by using data from cancer registries over a period of almost 30 years (1973-2000) [29]. Synchronous malignancies (tumours diagnosed within a 6-month period) are a very rare occurrence [30-39]. Only one small series of female breast cancers associated to axillary non-Hodgkin's lymphomas has previously been reported in the literature [25]. A family history of breast cancer was reported in $5 \%$ to $30 \%$ of cases $[40,41]$. Men with a positive history have been estimated to have an odds ratio for developing breast cancer of 3.98 [19]. Approximately $85 \%$ of patients experience a painless subareolar mass. Other common signs and symptoms include nipple retraction, local pain, nipple ulceration, and discharge $[18,21,42]$. Nipple involvement has been reported in $40 \%$ to $50 \%$ of cases, probably in relation to the paucity of breast tissue and the central location of most tumours [13, 14, 43]. Male breast cancers have many similarities with female malignancies, but the rarity of the disease precludes large clinical trials, in order to define standard treatments.

Actually, $90 \%$ of all male breast tumours are invasive ductal carcinomas, while the remaining $10 \%$ are noninvasive malignancies, mostly in situ ductal carcinoma [21]. Furthermore, if compared to women, men have a higher risk of developing a second breast cancer following a first malignancy in the same patient ( 1 out 100 cases) [10]. Hormonal and socioeconomic risk factors appear to be similar for both genders, while Klinefelter syndrome (possibly associated to BRCA2 genetic mutations), gynaecomastia, and testicular diseases represent specific additional risk factors for male patients [10]. Gene mutations predisposing to male breast cancer include the above mentioned BRCA2, BRCA1, and the androgen receptor gene, but an association has been shown only for prostatic, gastric, and pancreatic cancers [10]. Therefore, negative results of genetic tests performed in our patient are not surprising, because BRCA2 (and to some extent $B R C A 1$ ) mutations have been proposed only for correlation between male breast cancer and pancreatic or prostate cancers [10]. Also adjuvant locoregional radiotherapy was necessary $[9,16,20,29,31]$. The most important prognostic indicators are the cancer stage at diagnosis and lymph node 
status. The 5-year survival for stage III (corresponding to our patient classification) is estimated between 30 and $60 \%$.

Most studies suggest adjuvant hormonal therapy and chemotherapy to be started in intermediate or high risk patients $[9,16,20]$. In our patient, the histology of 22 excised axillary nodes confirmed breast cancer metastases and incidental large B cell lymphoma. Treatment included adjuvant chemotherapy with anthracyclines for the breast cancer and first-line therapy for large B cell lymphoma. Genetic counseling was performed, but no germline mutations were found. In treating our patient, standard guidelines issued for women were followed because of lack of similar guidelines for men.

Since men have higher response rates to additive hormonal therapy, this approach has been proposed as first-line treatment in hormone-receptor positive disease, tamoxifen being the front-line therapy choice [44]. Despite that, no randomised clinical trials have evaluated the use of adjuvant tamoxifen. Several large studies retrospectively compared men who were treated with tamoxifen in an adjuvant setting with men who received no hormonal therapy and found improved survival in patients in the first group [18, 44]. However, in our case the diagnoses of breast cancer and non-Hodgkin's lymphoma were simultaneous prior to the institution of any therapy. The presence of the lymphoma was unsuspected by the clinician, but its proper assessment allowed the patient to receive the proper therapy, based on anthracyclines. This is the first synchronous case reported in literature of male breast cancer and axillary lymphoma simultaneously confirmed in the same patient. In daily practice, we recommend that male patients with breast swelling (gynaecomastia) should receive genetic counseling concerning breast cancer, and undergo the same clinical staging and treatment as women.

\section{References}

[1] S. H. Landis, T. Murray, S. Bolden, and P. A. Wingo, "Cancer statistics in 1998," Ca-A Cancer Journal for Clinicians, vol. 48, no. 1, pp. 6-29, 1998.

[2] A. Anelli, T. F. M. Anelli, B. Youngson, P. P. Rosen, and P. I. Borgen, "Mutations of the p53 gene in male breast cancer," Cancer, vol. 75, no. 9, pp. 2233-2238, 1995.

[3] P. I. Borgen, G. Y. Wong, V. Vlamis et al., "Current management of male breast cancer: a review of 104 cases," Annals of Surgery, vol. 215, no. 5, pp. 451-459, 1992.

[4] T. D. Hill, H. J. Khamis, J. E. Tyczynski, and H. J. Berkel, “Comparison of male and female breast cancer incidence trends, tumor characteristics, and survival," Annals of Epidemiology, vol. 15, no. 10, pp. 773-780, 2005.

[5] A. Jemal, T. Murray, E. Ward et al., "Cancer statistics," $C a-A$ Cancer Journal for Clinicians, vol. 55, no. 1, pp. 10-30, 2005.

[6] M. Ewertz, L. Holmberg, S. Karjalainen, S. Tretli, and H. O. Adami, "Incidence of male breast cancer in Scandinavia, 19431982," International Journal of Cancer, vol. 43, no. 1, pp. 27-31, 1989.

[7] C. La Vecchia, F. Levi, and F. Lucchini, "Descriptive epidemiology of male breast cancer in Europe," International Journal of Cancer, vol. 51, no. 1, pp. 62-66, 1992.
[8] M. Ewertz, "Epidemiology of breast cancer: the nordic contribution," European Journal of Surgery, vol. 162, no. 2, pp. 97-99, 1996.

[9] R. Gennari, G. Curigliano, B. A. Jereczek-Fossa et al., "Male breast cancer: a special therapeutic problem. Anything new? (Review)," International Journal of Oncology, vol. 24, no. 3, pp. 663-670, 2004.

[10] K. Hemminki, G. Scélo, P. Boffetta et al., "Second primary malignancies in patients with male breast cancer," British Journal of Cancer, vol. 92, no. 7, pp. 1288-1292, 2005.

[11] R. Hultborn, C. Hanson, I. Köpf, I. Verbiené, E. Warnhammar, and A. Weimarck, "Prevalence of Klinefelter's syndrome in male breast cancer patients," Anticancer Research, vol. 17, no. 6, pp. 4293-4297, 1997.

[12] I. S. Fentiman, A. Fourquet, and G. N. Hortobagyi, "Male breast cancer," The Lancet, vol. 367, no. 9510, pp. 595-604, 2006.

[13] M. G. Joshi, A. K. C. Lee, M. Loda et al., "Male breast carcinoma: an evaluation of prognostic factors contributing to a poorer outcome," Cancer, vol. 77, no. 3, pp. 490-498, 1996.

[14] M. G. Joshi, A. K. C. Lee, M. Loda et al., "Male breast carcinoma: an evaluation of prognostic factors contributing to a poorer outcome," Annali Italiani Di Chirurgia, vol. 75, no. 6, 2004.

[15] N. Tajima, H. Tsukuma, and A. Oshima, "Descriptive epidemiology of male breast cancer in Osaka, Japan," Journal of Epidemiology, vol. 11, no. 1, pp. 1-7, 2001.

[16] K. Ouriel, M. T. Lotze, and J. R. Hinshaw, "Prognostic factors of carcinoma of the male breast," Surgery Gynecology and Obstetrics, vol. 159, no. 4, pp. 373-376, 1984.

[17] G. Ribeiro and R. Swindell, "Adjuvant tamoxifen for male breast cancer (MBC)," British Journal of Cancer, vol. 65, no. 2, pp. 252-254, 1992.

[18] G. G. Ribeiro, R. Swindell, M. Harris, S. S. Banerjee, and A. Cramer, "A review of the management of the male breast carcinoma based on an analysis of 420 treated cases," Breast, vol. 5, no. 3, pp. 141-146, 1996.

[19] K. A. Rosenblatt, D. B. Thomas, A. McTiernan et al., "Breast cancer in men: aspects of familial aggregation," Journal of the National Cancer Institute, vol. 83, no. 12, pp. 849-854, 1991.

[20] R. A. J. Spence, G. Mackenzie, J. R. Anderson, A. R. Lyons, and M. Bell, "Long-term survival following cancer of the male breast in Northern Ireland. A report of 81 cases," Cancer, vol. 55, no. 3, pp. 648-652, 1985.

[21] H. Stalsberg, D. B. Thomas, K. A. Rosenblatt et al., "Histologic types and hormone receptors in breast cancer in men: a population-based study in 282 United States men," Cancer Causes and Control, vol. 4, no. 2, pp. 143-151, 1993.

[22] M. Stierer, H. Rosen, W. Weitensfelder et al., "Male breast cancer: austrian experience," World Journal of Surgery, vol. 19, no. 5, pp. 687-692, 1995.

[23] C. Atalay, M. Kanlioz, and M. Altinok, "Prognostic factors affecting survival in male breast cancer," Journal of Experimental and Clinical Cancer Research, vol. 22, no. 1, pp. 29-33, 2003.

[24] D. B. Thomas, L. M. Jimenez, A. McTiernan et al., "Breast cancer in men: risk factors with hormonal implications," American Journal of Epidemiology, vol. 135, no. 7, pp. 734-748, 1992.

[25] J. Cox, L. Lunt, and L. Webb, "Synchronous presentation of breast carcinoma and lymphoma in the axillary nodes," Breast, vol. 15, no. 2, pp. 246-252, 2006.

[26] M. A. Shipp, D. P. Harrington, J. R. Andersen et al., "A predictive model for aggressive non-Hodgkin's lymphoma. 
The International Non-Hodgkin's Lymphoma Prognostic Factors Project," The New England Journal of Medicine, vol. 329, no. 14, pp. 987-994, 1993.

[27] K. Yoshimoto, M. Iizuka, H. Iwahana et al., "Loss of the same alleles of HRAS1 and D11S151 in two independent pancreatic cancers from a patient with multiple endocrine neoplasia type 1," Cancer Research, vol. 49, no. 10, pp. 2716-2721, 1989.

[28] K. M. Stavraky, T. A. Watson, D. F. White, and E. M. Miles, "Chronic lymphocytic leukemia and subsequent cancer in the same patient," Cancer, vol. 26, no. 2, pp. 410-414, 1970.

[29] R. E. Curtis, D. M. Freedman, E. Ron et al., Eds., New Malignancies Among Cancer Survivors: SEER Cancer Registries, 1973-2000, National Cancer Institute, National Institutes of Health, Bethesda, Md, USA, 2006.

[30] K. Oka, M. Shinonaga, R. Nagayama et al., "Coexistence of primary pulmonary Hodgkin lymphoma and gastric MALT lymphoma associated with Epstein-Barr virus infection: a case report," Pathology International, vol. 60, no. 7, pp. 520-523, 2010.

[31] A. O. Chan, K. M. Chu, S. T. Yuen et al., "Synchronous gastric adenocarcinoma and mucosa-associated lymphoid tissue lymphoma in association with Helicobacter pylori infection: comparing reported cases between the East and West," American Journal of Gastroenterology, vol. 96, no. 6, pp. 1922-1924, 2001.

[32] G. M. de Melo, D. A. Sguilar, C. M. F. Petiti, A. G. G. Eichstaedt, R. R. Caiado, and R. A. S. Souza, "Concomitant thyroid MALT lymphoma and papillary thyroid carcinoma," Arquivos Brasileiros de Endocrinologia e Metabologia, vol. 54, no. 4, pp. 425-428, 2010.

[33] I. G. Panayiotides, P. G. Foukas, C. Meristoudis, A. P. Zourla, G. Peros, and P. Karakitsos, "Simultaneous occurrence of Warthin-like papillary carcinoma and lymphoma of the mucosa associated lymphoid tissue in Hashimoto thyroiditis," Journal of Clinical Pathology, vol. 63, no. 7, pp. 662-663, 2010.

[34] F. Takeshima, M. Kunisaki, T. Aritomi et al., "Hepatic mucosaassociated lymphoid tissue lymphoma and hepatocellular carcinoma in a patient with hepatitis B virus infection," Journal of Clinical Gastroenterology, vol. 38, no. 9, pp. 823-826, 2004.

[35] N. Watanabe, H. Inohara, S. Akahani, Y. Yamamoto, K. Moriwaki, and T. Kubo, "Synchronous squamous cell carcinoma and malignant lymphoma in the head and neck region," Auris Nasus Larynx, vol. 34, no. 2, pp. 273-276, 2007.

[36] M. S. Tezer, U. Tuncel, S. Uzlugedik, M. Uzun, S. Kulaçoğlu, and A. Ünal, "Coexistence of laryngeal squamous cell carcinoma and non-Hodgkin's lymphoma with nasopharyngeal involvement," Journal of Laryngology and Otology, vol. 120, pp. 100-110, 2006.

[37] T. Koletsa, G. Petrakis, G. Karayannopoulou et al., "Synchronous presence of nasopharyngeal carcinoma and marginal zone(MALT-Type) B-cell lymphoma in the pharynx," Pathology Research International, vol. 2011, Article ID 340763, 5 pages, 2011.

[38] M. Castagna, P. Gaeta, M. Cecchi, G. L. Pagni, and R. Pingitore, "Bilateral synchronous testicular involvement in multiple myeloma. Case report and review of the literature," Tumori, vol. 83, no. 4, pp. 768-771, 1997.

[39] A. Cavaliere, G. Bellezza, M. Scheibel, R. Vitali, and A. Sidoni, "Biopathological profile of multiple synchronous homolateral and bilateral breast cancers," Pathology, Research and Practice, vol. 200, no. 1, pp. 9-12, 2004.
[40] B. D'Avanzo and C. La Vecchia, "Risk factors for male breast cancer," British Journal of Cancer, vol. 71, no. 6, pp. 1359-1362, 1995.

[41] J. G. Demeter, N. G. Waterman, and G. D. Verdi, "Familial male breast carcinoma," Cancer, vol. 65, no. 10, pp. 2342-2343, 1990.

[42] P. E. Goss, C. Reid, M. Pintilie, R. Lim, and N. Miller, "Male breast carcinoma: a review of 229 patients who presented to the Princess Margaret Hospital during 40 years: 1955-1996," Cancer, vol. 85, no. 3, pp. 629-639, 1999.

[43] H. Y. Yap, C. K. Tashima, G. R. Blumenschein, and N. E. Eckles, "Male breast cancer. A natural history study," Cancer, vol. 44, no. 2, pp. 748-754, 1979.

[44] E. Yildirim and U. Berberoglu, "Male breast cancer: a 22-year experience," European Journal of Surgical Oncology, vol. 24, no. 6, pp. 548-552, 1998. 


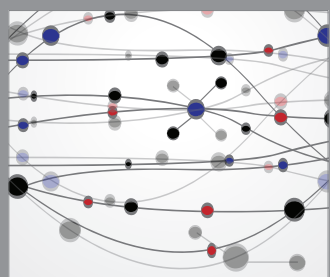

The Scientific World Journal
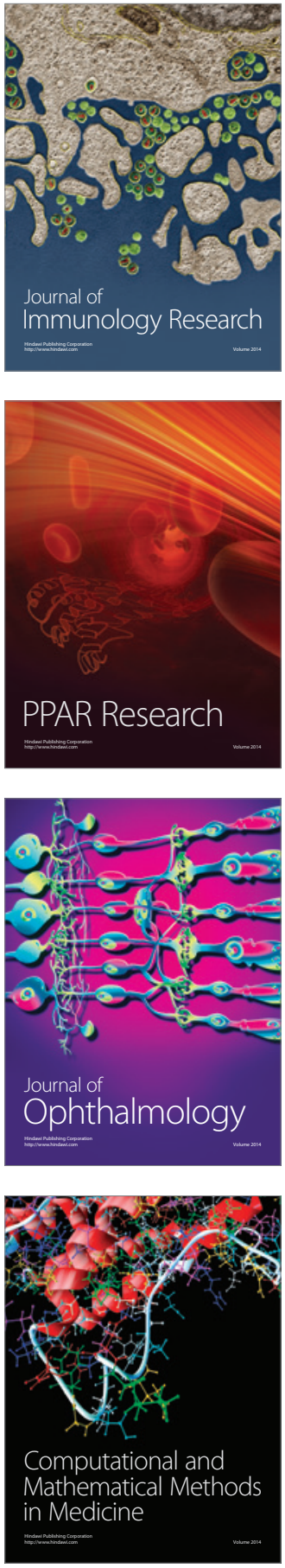

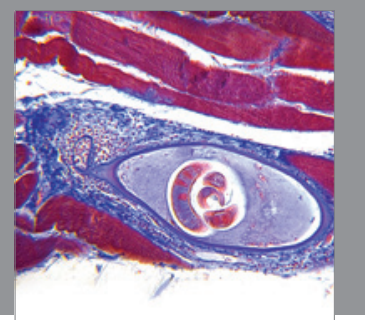

Gastroenterology

Research and Practice
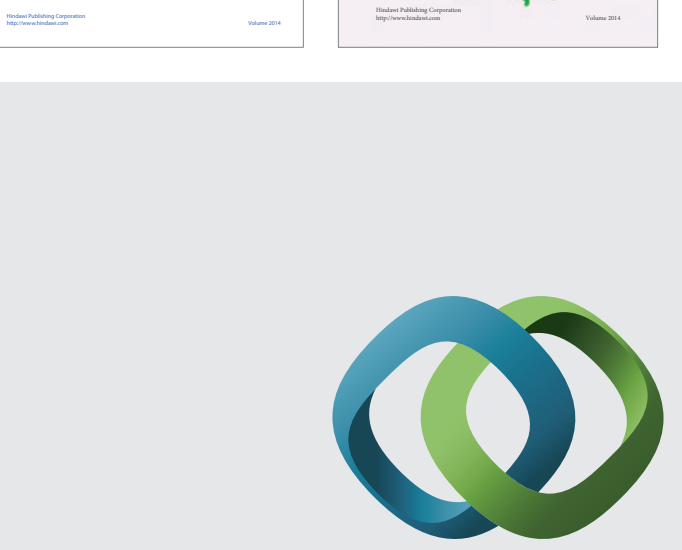

\section{Hindawi}

Submit your manuscripts at

http://www.hindawi.com
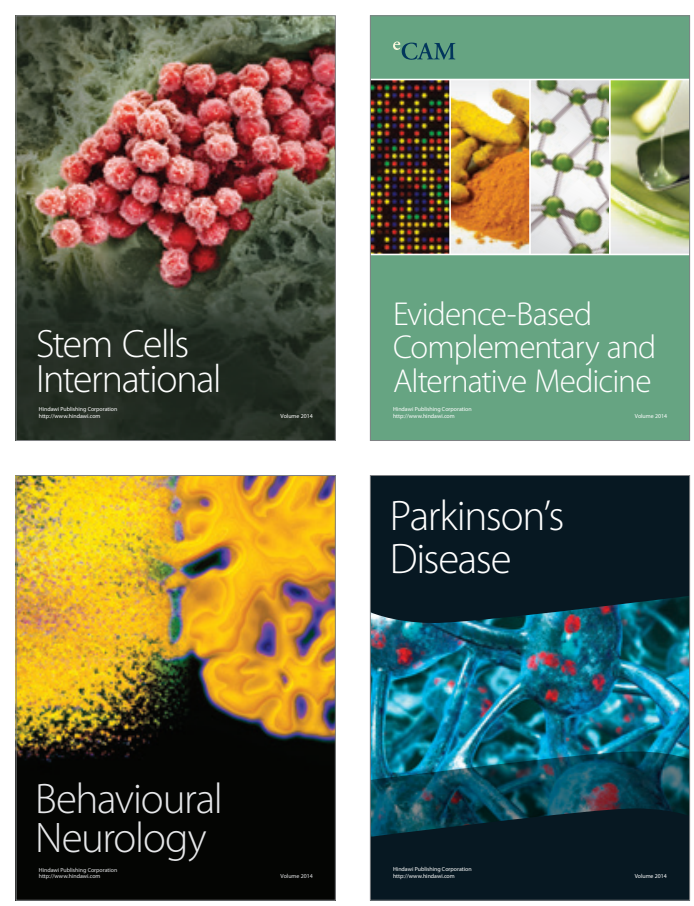

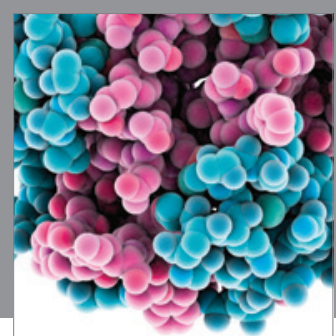

Journal of
Diabetes Research

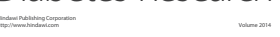

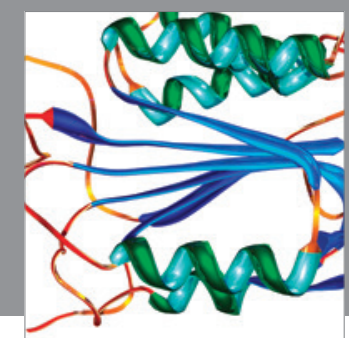

Disease Markers
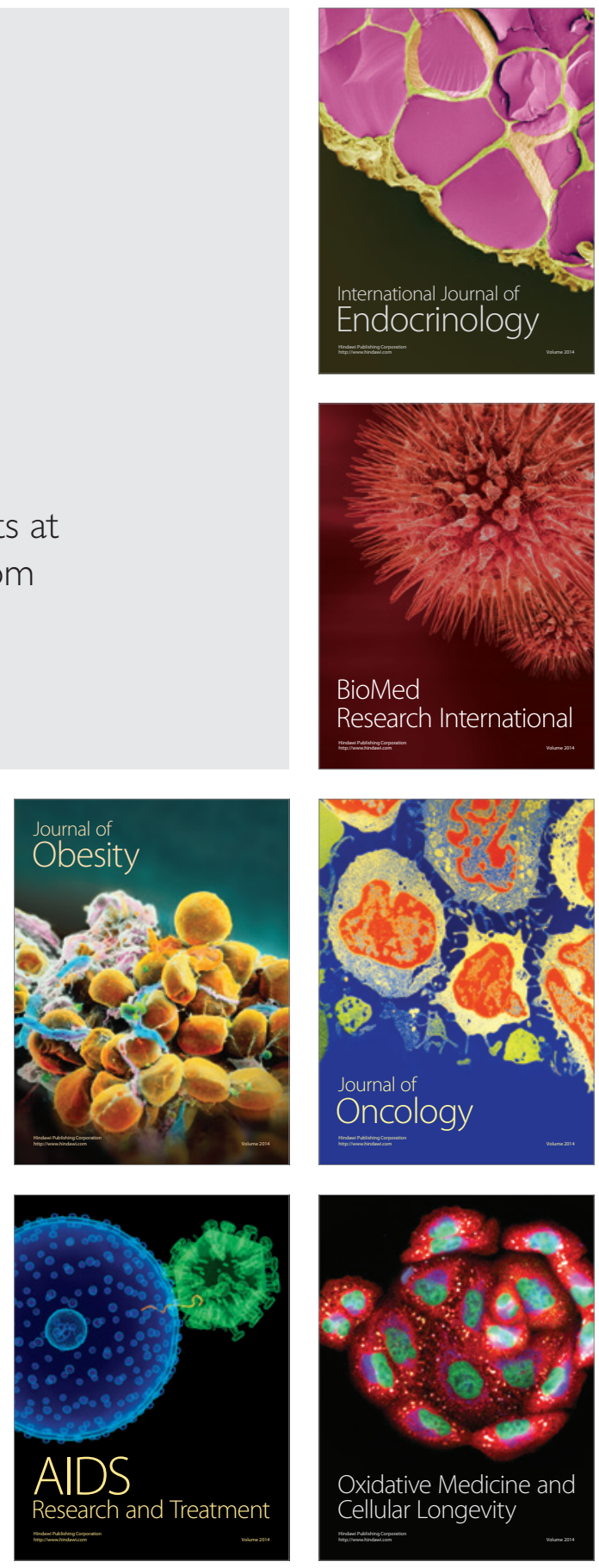